\title{
Limitaciones a la aplicación de cláusulas sociales en la contratación pública desde la perspectiva del derecho de la competencia
}

\author{
María José Vañó Vañó
}

\section{RESUMEN}

Las entidades pertenecientes al sector público, en cuanto agentes en el mercado intervienen, por una parte, como demandantes de bienes y servicios y, por otra, promoviendo procedimientos de contratación pública. Ambas actuaciones están sometidas a las reglas de la competencia, en particular, y en el ámbito de la contratación pública son las entidades públicas las que deben fomentar la competencia en los procedimientos, no incorporando restricciones injustificadas, ayudando a prevenir y a combatir potenciales actuaciones ilícitas entre las empresas oferentes en el proceso. Con sus actuaciones procompetitivas también puede colaborar la Comisión Nacional de los Mercados y de la Competencia. Los entes públicos deben facilitar el uso de cláusulas sociales en estos procedimientos de contratación. Por ello, en este trabajo desarrollaremos un análisis y propuesta de uso de las citadas cláusulas y otros criterios que nos permitan una discriminación positiva en favor de ciertos sectores, como por ejemplo, los que estén en riesgo de exclusión, sin que se alteren las reglas definidas por la Ley de Defensa de la Competencia y su Reglamento regulador.

PALABRAS CLAVE: Contratación pública, Cláusulas sociales, Defensa de la competencia, Políticas públicas.

CLAVES ECONLIT: K21, K20, J58, K12, K23, H57.

Cómo citar este artículo / How to cite this article: VAÑÓ, M.J. (2016): "Limitaciones a la aplicación de cláusulas sociales en la contratación pública desde la perspectiva del derecho de la competencia", CIRIEC-España, Revista de Economía Pública, Social y Cooperativa, 87, 177-202.

Correspondencia: Dra. María José Vañó Vañó, Profesora Titular de Universidad, Departamento de Derecho Mercantil "Manuel Broseta Pont", Investigadora del IUDESCOOP, Universitat de València, e-mail: Maria.J.Vano@uv.es. 


\section{EXPANDED ABSTRACT}

\section{Limits on social clauses in public procurement from the perspective of antitrust law}

The entities belonging to the public sector are involved as agents in the market, firstly, in procuring goods and services, and secondly, in initiating public procurement procedures.

Both actions are subject to the rules of competition, in particular, and in the field of public procurement it is the public entities that should encourage competition in their procedures by not incorporating unjustified restrictions and by helping to prevent and combat potential illegal actions between the bidding firms in the process. The guarantee of the principles of disclosure, competition, transparency, confidentiality, non-discrimination and safeguarding free competition are essential functions of public administrations, and nothing prevents other social principles from being incorporated into these procedures. In our analysis, we recommend avoiding those procedures in which there is no possibility of initiating a competitive process. With its pro-competitive proceedings, the National Antitrust Commission can also help, either by its own initiative or at the request of a party.

The Antitrust Commission, and the authorities that preceded it, have in recent years been developing numerous guides to support and safeguard these principles in the public procurement process.

If competition disappears, a decline in economic efficiency and a waste of public resources will occur, increasing the costs to be paid by public administrations.

The incorporation of stringent measures to safeguard competition in procurement procedures suggests that these instruments, economic and legal, and the transparency to which the use of Information and Communication Technologies will greatly contribute, will facilitate for public administrations the development and efficiency of public procurement.

Along with preventing these anti-competitive practices, the regulatory norms of the public sector contracts themselves will encourage the contracting authorities, the Advisory Board for Public Contracting of the State, and the bodies competent to rule on the special appeal that article 40 of the same law refers to, to be required to notify the Antitrust Commission of any fact they become aware of in the exercise of their functions, which may constitute a violation of the competition law, i.e. they must communicate "any sign of collective agreement, decision or recommendation, or concerted or consciously parallel practice among the bidders, whose object produces or may produce the effect of preventing, restricting or distorting competition in the procurement procedure." 
In Spain, the Antitrust Commission has observed the need to strengthen transparency in public procurement and to achieve greater efficiency on the part of the public authorities, which will contribute to increased cooperation between the institutions involved. It is considered that greater disclosure and transparency in the procurement procedures will facilitate access for the bidders. If, in addition, the public authorities clearly specify the characteristics of the procedures, the general and specific clauses and the contractual peculiarities affecting the chosen procedure, eliminating those selection criteria that are ambiguous or overly discretionary, and if the procedures that do not meet sufficient guarantees of disclosure are excluded, then the rules of competition will have been met.

The public administration should be aware of its ability to achieve objectives with respect to procurement that go beyond the work, supplies or services, and they should incorporate social purposes, although the use of social clauses is not without problems in public procurement.

Public authorities should ensure that there is full equality concerning access to information, as well as access to any facts related to the correction of errors in the different steps of the procedure. They must provide all information regarding any changes that arise, such as additional provisions or changes in prices.

The incorporation of social clauses in public procurement aims to generate employment opportunities, which means implementing social public policies aimed at more disadvantaged sectors and, for that reason, public authorities must facilitate the use of social clauses in these procurement procedures; however, the limitations imposed by the law in force in the field of public procurement, on the one hand, and the requirements imposed by competition law, on the other hand, require an analysis of the limitations imposed by the legislature, so that all actions which are not expressly prohibited will be permitted. With the addition of social clauses into the procurement process, the implementation of the social public policies of the state, regional or local authorities will be achieved and thereby favour certain sectors at risk of social exclusion, or assist non-profit entities that incorporate this objective into their articles.

For this reason, one object of analysis will be the recognition of certain advantages to those companies that either have people on staff with disabilities or who are at risk of social exclusion, or in the case of non-profit companies; preference in the awarding of contracts will be analyzed, provided that the proposals are on equal terms, with the most economically advantageous, to the regulated insertion companies, or the preference in the award of the contract recognized in relation to services of a social or assistance nature, for those proposals submitted by non-profit entities, with legal personality, and provided that their activity is directly related to the subject of the contract, and also special attention will be given to the establishment of special conditions to promote equality between women and men in the labour market, and the setting of minimum reserve percentages of the right to participate in the procedures for the awarding of certain contracts or certain batches of them to be given to Special Employment Centers and insertion companies. 
Thus, public administrations have the obligation to use public procurement rules, ensuring compliance with the principles of disclosure, competition, transparency, confidentiality, non-discrimination and protection of free competition, with nothing preventing other principles of a social nature from being incorporated into such proceedings. We therefore recommend avoiding those procedures in which there is no possibility of initiating a competitive process.

It is clear, therefore, that the determining factor in the awarding of the contract will not be the criterion of the lowest price, but rather the most advantageous economic proposal in which social and environmental criteria are included, as well as fair trade, gender equality and the inclusion of sectors at risk of social exclusion.

KEYWORDS: Public Procurement, Social Clauses, Antitrust, Public policies. 


\section{1.- Introducción1}

Las Administraciones Públicas actúan en el mercado como agentes económicos que pueden tomar decisiones y por tanto afectar al mismo, por lo que están sometidos a las reglas de la competencia. Además deberán velar porque los procedimientos se ajusten, no sólo a la normativa reguladora de los contratos del sector público, Real Decreto Legislativo 3/2011, de 14 de noviembre, por el que se aprueba el Texto Refundido de la Ley de Contratos del Sector Público (en adelante TRLCSP), sino también a las reglas de la competencia, promoviendo procedimientos abiertos, transparentes y competitivos (Vid. Guía sobre la Contratación Pública y Competencia de la Comisión Nacional de la Competencia, 2010, PRO/CNMC/001/15: Análisis de la contratación pública en España: oportunidades de mejora desde el punto de vista de la competencia, 2015 e IPN/CNMC/010/15 Anteproyecto de Ley de Contratos del Sector Público).

El punto de partida por tanto debe situarse en el tipo de procedimientos de contratación pública que deberán llevar a cabo los poderes públicos, con el fin de que cumplan con el dictado de las normas de defensa de la competencia, y promuevan procesos competitivos, transparentes, y abiertos, y cuyo objetivo deberá ser, en todo caso, la protección de las partes que participan en los mismos, así como la defensa de los usuarios de los mismos.

Por todo ello, debemos atender a cuáles son los procedimientos recomendables para llevar a cabo un procedimiento de contratación, que beneficie a todas las partes interesadas en el mismo, y que, por tanto, más se adecúa al respecto a las reglas de la competencia.

Junto a ello desarrollaremos los aspectos sociales de la contratación pública, es decir, el reconocimiento expreso por parte del legislador a la incorporación de cláusulas sociales con el fin de que se favorezca a determinados sectores en riesgo de exclusión social, o que se fomente, en todo caso la participación de entidades que pertenezcan al sector de la economía social, el comercio justo o la igualdad.

1.- Proyecto coordinado: El emprendimiento social ante la crisis del empleo y del bienestar social. Subproyecto 1: FACTORES NORMATIVOS Y DE POLITICAS PUBLICAS EN EL EXITO DE LA EMPRESA SOCIAL. NPIF - Programa Nacional de Proyectos de Investigación Fundamental, 7564 - Ministerio de Economía y Competitividad, DER2012-39223-C02-01. (2012-2015)

Proyecto: ECONOMIA COLABORATIVA, ECONOMIA SOCIAL Y BIENESTAR. NPIF - Programa Nacional de Proyectos de Investigación Fundamental- Ministerio de Economía y Competitividad, DER2015-65519-C2-1-R. (2015-2018). 


\section{2.- Contratación pública y defensa de la competencia}

Las autoridades públicas, en cuanto participan en el mercado, adjudicando contratos, provocan un impacto económico importante sobre el mismo, de hecho, en España, según el Observatorio de Contratación Pública se situaría aproximadamente en el 18,5\% del PIB2. Por ello, el sector público debe llevar a cabo procedimientos de contratación pública cada vez más transparentes, y deben ser más procompetitivos y económicamente eficientes con el fin de beneficiar a todas las partes del proceso, es decir, ciudadanos, empresas y las propias Administraciones Públicas ${ }^{3}$. La incorporación y respeto de las reglas de la libre competencia permitirá salvaguardar a todos los implicados en estos procesos, por lo que es fundamental el respeto a los principios incorporados a nuestro ordenamiento jurídico en relación a las licitaciones, la publicidad y la transparencia, la no discriminación y la igualdad de trato entre los oferentes.

A la promoción, supervisión y defensa de estas condiciones de acceso a la licitación han contribuido la CNMC y autoridades precedentes, que como acabamos de citar, han elaborado numerosos informes y guías con el fin de erradicar las conductas anticompetitivas en la contratación pública e iniciar procedimientos, en su caso sancionadores, contra aquellos actos que introduzcan obstáculos en la contratación pública y eliminen la competencia efectiva en el mercado.

\subsection{Procedimientos de contratación pública}

El art. 138 del TRLCSP reconoce cinco tipos de procedimientos de adjudicación de las licitaciones en las Administraciones Públicas, a saber, el procedimiento abierto, restringido, negociado, dialogo competitivo y concurso de proyectos. Pero junto a ellos y muy problemáticos desde el punto de vista de la defensa de la competencia se regulan los "contratos menores", adjudicados directamente al empresario con capacidad de obrar y habilitación legal necesaria para realizar la prestación y las encomiendas de gestión.

En los procedimientos de adjudicación, a través de los cuales se selecciona el "mejor" contratista 0 adjudicatario del contrato, es esencial la garantía del interés público con la incorporación de los principios de igualdad y transparencia (art. 139 TRLCSP) 4 .

2.- http://www.obcp.es/

3.- Vid. PRO/CNMC/001/15: Análisis de la contratación pública en España: oportunidades de mejora desde el punto de vista de la competencia, 2015.

4.- En el anterior texto regulador de los contratos del sector público se calificaba como principios cardinales de toda licitación a los principios de publicidad, competencia e igualdad de oportunidades, es el caso de la STS (Sala de lo Contencioso-Administrativo, Sección $4^{a}$ ) de 16 febrero 2010 (RJI2010|3964) y jurisprudencia allí mencionada. 
a) Procedimiento abierto: El procedimiento abierto se caracteriza fundamentalmente, por permitir que cualquier empresario pueda presentar una proposición y convertirse en licitador, en los términos en que se regula en los arts. 157 a 161 TRLCSP. En ningún caso podrán negociarse los términos del contrato en este tipo de procedimientos y serán los que respeten en todo caso los principios de publicidad, concurrencia, igualdad y no discriminación que presiden la contratación administrativa, por lo que desde el punto de vista de la Defensa de la Competencia es el procedimiento más recomendable 5 .

b) El procedimiento restringido exige que antes de realizar el anuncio de liquidación, el órgano de contratación fije unos criterios objetivos de solvencia, en base a los cuales seleccionará un mínimo de cinco candidatos que podrán presentar ofertas. Pero tampoco se permite la negociación de los términos contractuales entre licitadores y órgano de contratación (arts. 162 a 168).

c) El Procedimiento negociado podrá ser utilizado en supuestos expresamente determinados, en los términos regulados en los arts. 169 a 178. En este supuesto el órgano de contratación realiza consultas, y negocia las condiciones de los contratos con los licitadores, por tanto será más fácil evitar el cumplimiento de los principios de publicidad, concurrencia, igualdad y no discriminación que presiden la contratación administrativa, y por tanto, se convierta en un procedimiento arbitrario que afecte a la ineficiencia del gasto público. En el diseño de este procedimiento se debe emplear especial cuidado por parte de las AAPP para que no se introduzcan restricciones a la libre competencia.

d) El diálogo competitivo se prevé para la celebración de contratos con una alta complejidad, para lo cual, y siguiendo lo dispuesto en los art. 179 a 183 TRLCSP el órgano de contratación selecciona a un grupo de candidatos de entre las solicitudes recibidas, y dirige un diálogo entre ellos con el fin de establecer las bases para que los candidatos presenten sus ofertas, evitando en todo momento cualquier restricción a la libre competencia, como por ejemplo barreras de acceso al mercado o la fijación de precios.

e) En el caso del concurso de proyectos, desarrollado fundamentalmente en el ámbito de la arquitectura, urbanismo, ingeniería, o procesamiento de datos, se realiza una selección encomendada a un jurado, tras la correspondiente licitación (arts. 184 a 188 TRLCSP).

f) Junto a estos procedimientos de adjudicación se encuentran los contratos menores, que pueden ser directamente adjudicados a un empresario interesado, y son los que con mayor facilidad se pueden incumplir las reglas de defensa de la competencia, y deberán ajustarse a las reglas del art. 138.3 TRLCSP que señala,

5.- Vid. "Guía sobre contratación pública y competencia" (2010) y PRO/CNMC/001/15: Análisis de la contratación pública en España: oportunidades de mejora desde el punto de vista de la competencia (2015). GARCÍA ARÉJULA, J.M./ BAKAIKOA AZURMENDI, B. (2014), GARCÍA ARÉJULA, J.M./ BAKAIKOA AZURMENDI, B.(2016). BURZACO SAMPER, M. (2016). 
"Los contratos menores podrán adjudicarse directamente a cualquier empresario con capacidad de obrar y que cuente con la habilitación profesional necesaria para realizar la prestación, cumpliendo con las normas establecidas en el artículo 111.

Se consideran contratos menores los contratos de importe inferior a 50.000 euros, cuando se trate de contratos de obras, o a 18.000 euros, cuando se trate de otros contratos, sin perjuicio de lo dispuesto en el artículo 206 en relación con las obras, servicios y suministros centralizados en el ámbito estatal."

g) Por último, las encomiendas de gestión suelen ser muy utilizadas por las Administraciones Públicas para la prestación de servicios a través de entidades instrumentales, de derecho público 0 privado, que presentan una relación de dependencia con ella. Aunque excluidas expresamente del ámbito de aplicación del TRLCSP6, nos referimos a ellas por sus implicaciones desde el punto de vista de la defensa de la competencia?

\subsection{Contratación pública y defensa de la competencia}

La Comisión Nacional de los Mercados y de la Competencia (en adelante CNMC), y las autoridades que la precedieron, han ido elaborando en los últimos años numerosas guías de apoyo y de salvaguarda de estos principios en los procesos de contratación pública ${ }^{8}$, que permiten detectar, prevenir y sancionar conductas anticompetitivas ${ }^{9}$. Si la competencia desparece, se produce una merma de la eficiencia económica y un desaprovechamiento de los recursos públicos, incrementando los costes que deberán pagar las administraciones públicas. El riesgo de colusión se incrementa si existe menos competencia, detectándose prácticas irregulares, barreras de entrada al exigir grandes inversiones a realizar en concesiones públicas ${ }^{10}$, costes económicos, informacionales y jurídicos para par-

6.- El art. 24.1.n) TRLSP declara excluidos de esta norma, "Los negocios jurídicos en cuya virtud se encargue a una entidad que, conforme a lo señalado en el artículo 24.6, tenga atribuida la condición de medio propio y servicio técnico del mismo, la realización de una determinada prestación. No obstante, los contratos que deban celebrarse por las entidades que tengan la consideración de medio propio y servicio técnico para la realización de las prestaciones objeto del encargo quedarán sometidos a esta Ley, en los términos que sean procedentes de acuerdo con la naturaleza de la entidad que los celebre y el tipo y cuantía de los mismos, y, en todo caso, cuando se trate de contratos de obras, servicios o suministros cuyas cuantías superen los umbrales establecidos en la Sección 2. ${ }^{a}$ del Capítulo Il de este Título Preliminar, las entidades de derecho privado deberán observar para su preparación y adjudicación las reglas establecidas en los artículos 137.1 y 190."

7.- Vid. "Informe sobre los medios propios y las encomiendas de gestión: Implicaciones de su uso desde la óptica de la promoción de la competencia" (2013).

8. - A saber, la "Guía sobre contratación pública y competencia" (2010), la "Aplicación de la Guía de Contratación y Competencia a los procesos de licitación para la provisión de la sanidad pública en España" (2013), el "Informe sobre los medios propios y las encomiendas de gestión: Implicaciones de su uso desde la óptica de la promoción de la competencia" (2013), o los informes relativos a los pliegos de contratación de diferentes entes públicos, que pueden ser consultados en www.cnmc.es. Vid. BURZACO SAMPER, M. (2016).

9.- $A$ tales efectos se pueden destacar, entre otros, los siguientes expedientes: S/0383/11 Transporte sanitario conquense, SACAN/0012/11 Transporte Ayuntamiento Las Palmas, S/0329/11 Asfaltos Cantabria, S/0226/10 Licitaciones carreteras, S/0316/10 Sobres de papel, S/0429/12 Residuos.

10.- Vid. Sentencia Juzgado de lo Contencioso-Administrativo núm. 3 de Valencia, núm. 506/2013 de 16 diciembre. JUR 2014|110946 sobre la inclusión en el pliego de una cláusula de una disposición en virtud de la cual el adjudicatario haya de indemnizar a una empresa lo que considera el Juzgado, constituye una barrera de entrada a otros posibles licitadores, garantizando la sola concurrencia de ésta (PAREJO ALFONSO 2004).

CIRIEC-España, Revista de Economía Pública, Social y Cooperativa ISSN: 0213-8093

№ $87 / 2016$, pp. 177-202 


\section{LIMITACIONES A LA APLICACIÓN DE CLÁUSULAS SOCIALES EN LA CONTRATACIÓN PÚBLICA DESDE LA PERSPECTIVA DEL DERECHO DE LA COMPETENCIA}

ticipar en una licitación, la existencia de múltiples órganos de contratación con diferentes procedimientos o los problemas de información asimétrica y relaciones de agencia encadenadas, calculándose unas desviaciones medias, al alza, del $25 \%$ del presupuesto de la contratación pública ${ }^{11}$.

La incorporación de medidas estrictas de salvaguarda de la competencia en los procedimientos de contratación a través del TRLCSP, permite afirmar que con estos instrumentos, económicos, y jurídicos, y la transparencia a la cual contribuirá en gran medida el uso de las Tecnologías de la Información y Comunicación, facilitarán a las AAPP el desarrollo y eficiencia de la contratación pública.

Por ello, las entidades del sector público deben fomentar la competencia en los procedimientos de contratación pública evitando procedimientos que introduzcan restricciones injustificadas a la competencia, realizando un adecuado diseño del pliego, de las condiciones de adjudicación y detallando cómo deberá realizarse la ejecución del servicio o del proyecto, así como el control de la ejecución del mismo.

Junto a la prevención de estas prácticas anticompetitivas, la propia norma reguladora de los contratos del sector público, TRCSP promueve que los órganos de contratación, la Junta Consultiva de Contratación Administrativa del Estado (en adelante JCCA) y los órganos competentes para resolver el recurso especial a que se refiere el art. 40 de la misma norma, deberán notificar a la CNMC cualquier hecho que conozcan en el ejercicio de sus funciones, que pueda constituir una infracción a la legislación de defensa de la competencia, es decir, deberán comunicar "cualquier indicio de acuerdo, decisión o recomendación colectiva, o práctica concertada o conscientemente paralela entre los licitadores, que tenga por objeto, produzca o pueda producir el efecto de impedir, restringir o falsear la competencia en el proceso de contratación".

De todos los procedimientos de adjudicación mencionados en el apartado anterior, son los procedimientos abiertos los que permiten cumplir con todos los principios que resultan esenciales para considerar que se cumplen con las reglas de la competencia. Sin embargo, habrá que analizar las cuestiones concretas relativas al diseño del pliego de condiciones, adjudicación y ejecución del contrato, fases del procedimiento en las que se podrán incorporar condiciones que infrinjan el derecho de defensa de la competencia. Evidentemente, los procedimientos negociados, restringidos, o competitivos,... son los que con mayor facilidad pueden incorporar restricciones a la libre competencia, si además las AAPP utilizan las encomiendas de gestión o contratos menores, se podrán alterar en mayor medida las reglas de defensa de la competencia y con ello, incrementar el gasto público, y reducir la confianza de los ciudadanos en el sector público.

11.- Vid. PRO/CNMC/001/15: Análisis de la contratación pública en España: oportunidades de mejora desde el punto de vista de la competencia, 2015. 
En España se ha manifestado por parte de la CNMC la necesidad de fortalecer la transparencia en la contratación pública, y conseguir una mayor eficiencia por parte de las AAPP a lo que contribuirá el incremento de la colaboración entre las instituciones implicadas. Se considera, que una mayor publicidad y transparencia en los procedimientos de contratación facilitará el acceso a las licitaciones. Si se concretan además de manera clara, las características de los procedimientos, las cláusulas generales y específicas y las peculiaridades contractuales, motivando el procedimiento elegido, eliminando criterios de selección ambiguos o excesivamente discrecionales, y se evitan los procedimientos que no reúnan las garantías suficientes de publicidad, se logrará cumplir con la normativa de defensa de la competencia. Así mismo, limitar a situaciones excepcionales la no publicación previa del anuncio de licitación en procedimientos negociados, por ejemplo, puede ser una buena solución ${ }^{12}$. 0 la supresión de sistemas de valoración poco claros o excesivamente subjetivos, no fomentar el acceso a la información al máximo de operadores, o que no esté disponible toda la información del procedimiento para todos los operadores potencialmente interesados ${ }^{13}$.

También se recomendaba por la $\mathrm{CNC}^{14}$, evitar extralimitaciones en la adjudicación de contratos a través de las encomiendas, y valorar en qué medida el mercado presta o puede prestar los bienes o servicios objeto de contrato, proponiendo el uso de la encomienda si los precios de mercado resultaren potencialmente inferiores.

En este punto debemos recordar que el TRLCSP, artículo 24.6, primer párrafo únicamente enuncia los requisitos del poder adjudicador sobre el ente adjudicado, en particular, el "control análogo" al que tienen sobre sus propios servicios "si pueden conferirles encomiendas de gestión que sean de ejecución obligatoria para ellos"15.

En cualquier caso, la figura de la encomienda contiene, de manera consustancial, aspectos restrictivos de la competencia. La propia limitación del acceso a terceros, al limitar la adjudicación a medios propios, entidades de naturaleza jurídica pública o privada, para la obtención de prestaciones que podrían ser objeto de contratación pública, tratándose de una operación interna, por lo que se elimina

12.- En este sentido se ha recogido en el Considerando 50 y artículo 32 de la Directiva 2014/24.

13.- Este último punto se puede resolver con la obligación a las AAPP de que utilicen el portal de contratación pública en todo caso, y para todo tipo de contratos (https://contrataciondelestado.es/wps/portal/plataforma). En el actual TRLCSP se establece la obligatoriedad de todos los órganos de contratación, tanto centrales como periféricos, organismos autónomos y restantes Entidades de Derecho Público, de enviar la información relativa a los contratos adjudicados, al Registro Público de Contratos de la Junta Consultiva de Contratación Administrativa (http://www.minhap.gob.es/es-

ES/Servicios/Contratacion/Junta\%20Consultiva\%20de\%20Contratacion\%20Administrativa/Paginas/Registro\%20publico\%20de\%20contratos. aspx). Vid en similar sentido PRO/CNMC/001/15: Análisis de la contratación pública en España: oportunidades de mejora desde el punto de vista de la competencia, 2015, pp. 11 y ss. y a lo que contribuirá en todo caso la Ley 19/2013, de 9 de diciembre, de Transparencia, Acceso a la Información Pública y Buen Gobierno (BOE 10 diciembre).

14.- Vid. Guía de la CNC sobre contratación pública y competencia (2011).

15. - La jurisprudencia europea ha permitido desarrollar este concepto circular de encomienda y control análogo, en varias sentencias considerando que debe tratarse de un control efectivo, funcional y no meramente formal. Así, vid. STJCE de 18.11.1999 asunto C-107/98 Teckal, STJCE 11.05.2006 asunto C.340/04 Carbotermo, STJCE 19.04.2007 asunto C-295/05 Asemfo/Tragsa, STJCE 13.11.2008 asunto 324/07 Coditel Brabant, y STJUE de 29.11.2012 asuntos C-182/11 y C-183/11 Econord SpA entre otras. 


\section{LIMITACIONES A LA APLICACIÓN DE CLÁUSULAS SOCIALES EN LA CONTRATACIÓN PÚBLICA DESDE LA PERSPECTIVA DEL DERECHO DE LA COMPETENCIA}

la posibilidad de participación competitiva de los operadores, con el objetivo de conseguir la oferta económicamente más ventajosa y logrando una mayor eficiencia en el uso de los recursos públicos ${ }^{16}$.

Con la encomienda de gestión se puede producir un efecto de cierre del mercado al asignar "a medios propios, encomiendas "marco" globales, incluyendo la posibilidad de desarrollar multitud de prestaciones a lo largo de un periodo temporal amplio, normalmente plurianual, cuya ejecución no necesariamente se puede anticipar en el momento de la encomienda. En todo caso, no siempre estas prestaciones, individualmente consideradas, guardan una vinculación entre sí que motive, o haga más eficiente, su asignación "en bloque" a una única entidad, en este caso un medio propio."17 La fijación de plazos demasiado amplios para la duración de las mismas, también es un elemento que impide el acceso al mercado de estos servicios u obtención de productos a oferentes privados. Otro elemento objeto de crítica es la subcontratación que realizan los medios propios, y que realizan a causa de "la falta de medios para desarrollarla". Si la subcontratación de la prestación se realiza con las garantías de publicidad y concurrencia, no se produciría ninguna restricción de la competencia, sin embargo, no es lo que habitualmente ocurre en este punto. El art. 4.1.n del TRLCSP regula los contratos que deban celebrarse por medios propios para la realización de las prestaciones objeto del encargo, quedando sometidos a esta norma.

Por otra parte, la ausencia de publicidad, transparencia y centralización de la información de las encomiendas, impide que se puedan comparar las operaciones llevadas a cabo a través de las mismas, desde el punto de vista económico, incluso social.

Al no existir competencia, puede impedir que se consigan ventajas económicas o rebajas de precios que sí se obtienen en las licitaciones públicas con procedimientos abiertos ${ }^{18}$. Aunque lo cierto es que, según indica el art. 24.6TRLCSP, la retribución de las encomiendas de gestión utilizará como referencia las tarifas aprobadas por la entidad pública de la que dependen, por tanto, sin ninguna posibilidad de negociación de los precios con el fin de obtener ventajas económicas ni incentivo de los órganos encomendantes para realizar una determinación precisa de su coste, aunque, se puede y debe exigir una análisis de los mismos para obtener un precio más eficiente del servicio.

Por último, y en relación a los contratos menores ${ }^{19}$, debemos recordar los contratos menores, que tal y como hemos apuntado anteriormente, son una práctica habitual de las AAPP y que se recogen en el TRLCSP, art. 23. 3. "Los contratos menores definidos en el artículo 138.3 no podrán tener una

16.- Vid en el mismo sentido, (GÓMEZ ASENSIO 2012 y VAÑÓ VAÑÓ, 2014).

17.- $P R O / C N M C / 001 / 15$ : Análisis de la contratación pública en España: oportunidades de mejora desde el punto de vista de la competencia, 2015.

18.- Vid. el análisis llevado a cabo en el "Informe sobre los medios propios y las encomiendas de gestión: Implicaciones de su uso desde la óptica de la promoción de la competencia" (2013) por la CNMC, p. 41 en el que el porcentaje a la baja del precio entre el de licitación y el de adjudicación en los casos de procedimientos abiertos se sitúa alrededor del $20 \%$, mientras que en procedimientos negociados sin publicidad, la diferencia se sitúa entre un 0,03 y un 3,96\%.

19.- VId. IPN/CNMC/010/15 INFORME SOBRE EL ANTEPROYECTO DE LEY DE CONTRATOS DEL SECTOR PÚBLICO. 
duración superior a un año ni ser objeto de prórroga." 20 Con este tipo de contratación se trata de evitar, por parte de las AAPP la utilización de procedimientos en los que se cumplan los preceptivos requisitos de igualdad, concurrencia, transparencia y no discriminación. Pero estas mismas AAPP con el fin de evitar estos procedimientos, llevan a cabo el fraccionamiento del objeto del contrato, y todo ello, a pesar de que el art. 86.2 TRLCSP reconoce que "no podrá fraccionarse un contrato con la finalidad de disminuir la cuantía del mismo y eludir así los requisitos de publicidad o los relativos al procedimiento de adjudicación que correspondan"21.

En este punto, no obstante debemos referirnos a lo dispuesto en el art. 46 de la DIRECTIVA 2014/24/UE DEL PARLAMENTO EUROPEO Y DEL CONSEJO de 26 de febrero de 2014 sobre contratación pública y por la que se deroga la Directiva 2004/18/CE en la que, con el fin de facilitar el acceso a las pequeñas y medianas empresas a la contratación pública, establece la posibilidad de dividir en lotes determinados contratos, incluso se puede imponer, en determinados casos, el fraccionamiento de los contratos. Así, el art. 86. 3. establece, "cuando el objeto del contrato admita fraccionamiento y así se justifique debidamente en el expediente, podrá preverse la realización independiente de cada una de sus partes mediante su división en lotes, siempre que éstos sean susceptibles de utilización o aprovechamiento separado y constituyan una unidad funcional, o así lo exija la naturaleza del objeto.

Asimismo, podrán contratarse separadamente prestaciones diferenciadas dirigidas a integrarse en una obra, tal y como ésta es definida en el artículo 6, cuando dichas prestaciones gocen de una sustantividad propia que permita una ejecución separada, por tener que ser realizadas por empresas que cuenten con una determinada habilitación.

En los casos previstos en los párrafos anteriores, las normas procedimentales y de publicidad que deben aplicarse en la adjudicación de cada lote o prestación diferenciada se determinarán en función del valor acumulado del conjunto, salvo lo dispuesto en los artículos 14.2, 15.2 y 16.2".

En cuanto al fomento de la participación en la contratación pública de pequeñas y medianas empresas, el art. 22 del TRLCSP señala en su apartado 2., que "Ios entes, organismos y entidades del sector público velarán por la eficiencia y el mantenimiento de los términos acordados en la ejecución de los procesos de contratación pública, favorecerán la agilización de trámites, valorarán la innovación y la incorporación de alta tecnología como aspectos positivos en los procedimientos de contra-

20.- Se trata de contratos que han sido criticados por la doctrina y por los informes elaborados por las Juntas de Contratación en numerosos informes, a saber, entre otros, MORENO MOLINA y PLEITE GUADAMILLAS (2011).

21.- Vid. RIERA LOPEZ (2013) y BURZACO SAMPER, M. (2016). Sirva como ejemplo, pueden verse el Informe de la JCCA núm. 57/08, de 31 de marzo de 2009, en el que rechazaba que el Ayuntamiento construyera una residencia geriátrica a través de la contratación de mínimas unidades y objetos. O por ejemplo, tampoco se admitió que la contratación para pavimentar varias aceras del Ayuntamiento se celebrara de manera independiente, como lotes. El argumento dado por el Ayuntamiento y no aceptado por la JCCA fue que existía una finalidad única, la mejora de las aceras, que eran calles distintas y que querían beneficiar y contratar con las pequeñas y medianas empresas del municipio (Informe 31/12, de 7 de mayo de 2013). 


\section{LIMITACIONES A LA APLICACIÓN DE CLÁUSULAS SOCIALES EN LA CONTRATACIÓN PÚBLICA DESDE LA PERSPECTIVA DEL DERECHO DE LA COMPETENCIA}

tación pública y promoverán la participación de la pequeña y mediana empresa y el acceso sin coste a la información, en los términos previstos en la presente Ley". Su reconocimiento, aún en abstracto, sin concretar las vías para la participación real de estas entidades, también se encuentra recogido en el artículo 102, relativo a la devolución y cancelación de las garantías, en el que establece en su apartado 5, que "transcurrido un año desde la fecha de terminación del contrato, sin que la recepción formal y la liquidación hubiesen tenido lugar por causas no imputables al contratista, se procederá, sin más demora, a la devolución o cancelación de las garantías una vez depuradas las responsabilidades a que se refiere el artículo 100. Cuando el importe del contrato sea inferior a 1.000.000 de euros, si se trata de contratos de obras, o a 100.000 euros, en el caso de otros contratos, o cuando las empresas licitadoras reúnan los requisitos de pequeña o mediana empresa, definida según lo establecido en el Reglamento (CE) n. ${ }^{\circ} 800 / 2008$, de la Comisión, de 6 de agosto de 2008, por el que se declaran determinadas categorías de ayuda compatibles con el mercado común en aplicación de los artículos 107 y 108 del Tratado y no estén controladas directa o indirectamente por otra empresa que no cumpla tales requisitos, el plazo se reducirá a seis meses."

A ello debemos añadir la Disposición final quinta que, bajo el título, "Fomento de la contratación precomercial", admite la posibilidad de que el Consejo de Ministros, mediante acuerdo, "fije dentro de los presupuestos de cada Departamento ministerial y de cada Organismo público vinculado con o dependiente de la Administración General del Estado, las cuantías necesariamente destinadas a la financiación de contratos a los que hace referencia el artículo 4.1.r) de esta Ley. Una parte de las mismas podrá reservarse a pequeñas y medianas empresas innovadoras".

\section{3.- Cláusulas sociales en la contratación pública}

La incorporación de cláusulas sociales en la contratación pública pretende generar oportunidades de empleo, lo que implica llevar a cabo políticas públicas sociales, dirigidas a sectores más desfavorecidos $^{22}$. Aunque este tipo de actuaciones no son el único recurso para eliminar la exclusión social,

22.- Sirvan como ejemplo la SSTS de 18 junio 1985. RJ $1985 \mid 3250$ relativa a "la necesidad de escoger la oferta más ventajosa no sólo económicamente y la Sentencia de 11 mayo 1999. RJ 1999|5029 cuando indica que "la Administración no puede adjudicar el concurso a cualquiera, sino que ha de atenerse a la oferta más ventajosa, pero no siendo sólo determinante el valor económico". O más recientemente, la Sentencia núm. 317/2014 de 24 noviembre. RJCA 2015|144, del Juzgado de lo Contencioso-Administrativo núm. 2 de Barcelona (Comunidad Autónoma de Cataluña) establece, "(d)e otra parte, el artículo 150 del TRLCSP dispone que para la valoración de las proposiciones y la determinación de la oferta económicamente más ventajosa deberá atenderse a criterios directamente vinculados al objeto del contrato, tales como la calidad, el precio , la fórmula utilizable para revisar las retribuciones ligadas a la utilización de la obra o a la prestación del servicio, el plazo de ejecución o entrega de la prestación, el coste de utilización, las características medioambientales o vinculadas con la satisfacción de exigencias sociales que respondan a necesidades, definidas en las especificaciones del contrato, propias de las categorías de población especialmente desfavorecidas a las que pertenezcan los usuarios o beneficiarios de las prestaciones a contratar, la rentabilidad, el valor técnico, las características estéticas o funcionales, la disponibilidad y coste de los repuestos, el mantenimiento, la asistencia técnica, el servicio postventa u otros semejantes." 
lo cierto es que son una herramienta que permitirá lograrlo a través de programas de inserción sociolaboral. Por ello, tal y como hemos apuntado anteriormente, los poderes públicos, en tanto agentes económicos, pueden afectar con sus actuaciones al mercado, y, por tanto, no solo en el ámbito de la contratación pública, sino también en cuanto a las políticas de inserción sociolaboral. En este punto, es importante que los entes públicos entiendan que la legislación en materia de contratos del sector público, y otra legislación sectorial, les ofrece la posibilidad de fijar reservas a favor de colectivos en riesgo de exclusión o a colectivos de discapacitados, siempre que cuenten con una previsión legal expresa que la justifique, por tanto, estaría este supuesto, al margen de la Ley de Defensa de la Competencia23. Las AAPP deben tomar conciencia de su capacidad para lograr objetivos con la contratación, que vayan más allá de la obra, del suministro o de los servicios, deben incorporar fines sociales, aunque no esté exenta de problemas la utilización de cláusulas sociales en la contratación pública24.

\subsection{Cláusulas relativas a personas con discapacidad o en riesgo de exclusión}

Actualmente, se reconoce de manera expresa la incorporación de cláusulas sociales en los contratos del sector público. En particular el TRLCSP, en la DA $4^{a}$ admite que podrán reconocerse ciertas ventajas a aquellas empresas que, o bien tengan en su plantilla a personas con discapacidad 0 en situación de exclusión social, o bien se trate de empresas sin ánimo de lucro. Por ello se ordena que los órganos de contratación ponderen, que los licitadores cumplan con lo previsto en el RDLeg. 1/2013 de 29 Nov. (aprueba el Texto Refundido de la Ley General de derechos de las personas con discapacidad y de su inclusión social) ${ }^{25}$. Es decir, que cuenten con un número de trabajadores determinado con discapacidad o que se adopten las medidas alternativas correspondientes. Por ello, los pliegos de las cláusulas administrativas particulares podrán incorporar una cláusula por la que se obligue a aportar a los licitadores, el certificado de la empresa en que conste el número global de trabajadores de plantilla, el de trabajadores con discapacidad, o las medidas alternativas legalmente previstas.

Del mismo modo, reconoce esta norma, que los órganos de contratación podrán señalar en los pliegos de cláusulas administrativas particulares, "la preferencia en la adjudicación de los contratos para las proposiciones presentadas por aquellas empresas públicas o privadas que, en el momento de acreditar su solvencia técnica, tengan en su plantilla un número de trabajadores con discapacidad superior al 2 por ciento, siempre que dichas proposiciones igualen en sus términos a las más ventajosas desde el punto de vista de los criterios que sirvan de base para la adjudicación". En caso de empate, tendrá preferencia en la adjudicación, aquella que acredite que dispone de mayor porcentaje de trabajadores fijos con discapacidad en su plantilla.

23.- En este punto, debemos recordar lo dispuesto en las Sentencias de 5 de mayo de 1983 y de 16 de julio de 1987 en las que se indicaba que "el principio de igualdad permite el tratamiento desigual ante situaciones de hecho desiguales" y que "la actuación de los poderes públicos para poner remedio a la situación de determinados grupos sociales en innegable desventaja en el ámbito laboral no puede considerarse vulneradora del principio de igualdad".

24.- (MEDINA JURADO 2010. BURZACO SAMPER 2016:281-310).

25.- Que sustituye a la Ley 13/1982, de 3 de abril de Integración Social de los minusválidos. 


\section{LIMITACIONES A LA APLICACIÓN DE CLÁUSULAS SOCIALES EN LA CONTRATACIÓN PÚBLICA DESDE LA PERSPECTIVA DEL DERECHO DE LA COMPETENCIA}

\subsection{Cláusulas sociales por razón del objeto}

También establece la preferencia en la adjudicación de contratos, siempre que las propuestas estén en igualdad de condiciones, con las económicamente más ventajosas, a las empresas de inserción reguladas en la Ley 44/2007, de 13 de diciembre y que cumplan con los requisitos establecidos por esta normativa para ser calificadas como tales. Otro criterio de preferencia en la adjudicación del contrato se reconoce en cuanto a los servicios de carácter social o asistencial, por las propuestas presentadas por entidades sin ánimo de lucro, con personalidad jurídica, y siempre que su actividad esté directamente relacionada con el objeto del contrato, requiriéndose para su justificación la aportación de los estatutos sociales donde se contempla su actividad u objeto social26. En este punto sería posible favorecer a entidades sin ánimo de lucro, a saber, empresas sociales o cooperativas sin ánimo de lucro, si su actividad u objeto social incorporaran algunos de estos objetivos. Por último, regula la preferencia en la adjudicación a aquellas empresas "que tengan como objeto productos en los que exista alternativa de comercio justo para las proposiciones presentadas por aquellas entidades reconocidas como Organizaciones de Comercio Justo, siempre que dichas proposiciones iguales en sus términos a las más ventajosas desde el punto de vista de los criterios que sirvan de base para la adjudicación".

Por todo ello, podemos afirmar que la inclusión de cláusulas sociales en los pliegos de condiciones es posible, siempre que se someta a un procedimiento y a unos criterios de adjudicación similares, equitativos y no discriminatorios 27.

Estos criterios podrán introducirse, tal y como hemos señalado, como cláusulas de preferencia en la adjudicación. Desde el punto de vista legal y fuera de los denominados contratos reservados para personas discapacitadas, no podrán incorporarse como requisitos previos, es decir, como criterios de admisión o selección en la contratación pública.

26.- Vid. Informe núm. 1/2012 de 20 de noviembre, JCCA en el que se formulaba una consulta acerca de la aplicación de preferencias a favor de empresas vinculadas con la atención de personas en situación de dependencia o de reservas de contratos, además de la establecida en la disposición adicional séptima de la LCSP de 2011. Aunque esta consulta estaba relacionada con la prestación de servicios sociales mediante convenio de colaboración, no es menos cierto que, por lo que a nosotros nos interesa, es plenamente aplicable, esto es, la posibilidad de poder justificar "el otorgamiento de alguna forma de preferencia o la reserva de algunos contratos a las entidades del sector social, con independencia de las posibilidades de reserva potestativa contempladas en la DA $7^{a}$ LCSP". En este punto la JCCA señala que la respuesta debe ser negativa, a lo que añade que "la reserva a Centros Especiales de Empleo actualmente prevista en la disposición adicional quinta del TRLCSP constituye una excepción al régimen de licitación previsto con carácter general para los contratos de las Administraciones Públicas, por motivos de carácter social. Como tal excepción es objeto de regulación expresa en el TRLCSP, recogiendo lo dispuesto también expresamente en la Directiva 2004/18/CE del Parlamento Europeo y del Consejo de 31 de marzo de 2004 (LCEur 2004, 1837) sobre coordinación de los procedimientos de adjudicación de los contratos públicos de obras, de suministro y de servicio, resultando motivada en que, en condiciones normales de competencia, estos talleres pueden tener dificultades para obtener contratos." Por todo ello, concluye que "no existiendo previsión expresa en el TRLCSP respecto a la posibilidad de reservar a las entidades del tercer sector determinados contratos, no resulta admisible esta reserva sobre la base de los principios consignados en la Ley 39/2006, de 14 de diciembre de Promoción de la Autonomía Personal y Atención a las Personas en situación de Dependencia, debiéndose aplicar las reglas generales que regulan el contrato de gestión de servicios públicos."

27.- PANIAGUA ZURERA 2013. LESMES ZABALEGUI 2005:53-86. BURZACO SAMPER 2016:281-310. 


\subsection{Cláusulas de igualdad de mujeres y hombres}

Si bien desde la legislación vigente, se conceptualiza la igualdad de mujeres y hombres, y se fomentan políticas de igualdad, no es menos cierto que su uso en el ámbito de la contratación pública sigue teniendo problemas de aplicación, quizás por desconocimiento de los poderes públicos 28 .

Si bien la Ley Orgánica 3/2007, de 22 de marzo, para la igualdad efectiva de mujeres y hombres (vigente hasta el 01 de Enero de 2017) regula el reconocimiento de políticas de fomento en sus arts. 33 y 34 a través de sus órganos de contratación, y en relación con la ejecución de los contratos que celebren, establece que podrán establecer condiciones especiales para promover la igualdad entre mujeres y hombres en el mercado de trabajo de acuerdo con lo dispuesto en el TRLCSP, ordenando al Consejo de Ministros a que, a la vista de la evolución e impacto de las políticas de igualdad en el mercado laboral, determine los contratos del sector público que obligatoriamente deberán incluir entre sus condiciones de ejecución medidas tendentes a promover la igualdad efectiva, lo cierto es que no se ha generalizado su utilización y están siendo objeto de consulta en los órganos consultivos autonómicos y centrales, para proceder a su aplicación. Esta norma, Ley Orgánica 3/2007, de 22 de marzo, además permite que los órganos de contratación establezcan en los pliegos de cláusulas administrativas particulares, "la preferencia en la adjudicación de los contratos de las proposiciones presentadas por aquellas empresas que, en el momento de acreditar su solvencia técnica o profesional, cumplan con las directrices del apartado anterior, siempre que estas proposiciones igualen en sus términos a las más ventajosas desde el punto de vista de los criterios objetivos que sirvan de base a la adjudicación y respetando, en todo caso, la prelación establecida en el apartado primero de la disposición adicional octava del Texto Refundido de la Ley de Contratos de las Administraciones Públicas, aprobado por Real Decreto Legislativo 2/2000, de 16 de junio."

Por otra parte, atendiendo a lo dispuesto en el art. 118 TRLCSP se permite la inclusión de condiciones especiales de ejecución del contrato, siempre que sean compatibles con el derecho comunitario y se indiquen en el anuncio de licitación y en el pliego o en el contrato. A lo que añade, "(e)stas condiciones de ejecución podrán referirse, en especial, a consideraciones de tipo medioambiental o a consideraciones de tipo social, con el fin de promover el empleo de personas con dificultades particulares de inserción en el mercado laboral, eliminar las desigualdades entre el hombre y la mujer en dicho mercado, combatir el paro, favorecer la formación en el lugar de trabajo, u otras finalidades que se establezcan con referencia a la estrategia coordinada para el empleo, definida en el artículo 145 del Tratado de Funcionamiento de la Unión Europea, o garantizar el respeto a los derechos labora- 


\section{LIMITACIONES A LA APLICACIÓN DE CLÁUSULAS SOCIALES EN LA CONTRATACIÓN PÚBLICA DESDE LA PERSPECTIVA DEL DERECHO DE LA COMPETENCIA}

les básicos a lo largo de la cadena de producción mediante la exigencia del cumplimiento de las Convenciones fundamentales de la Organización Internacional del Trabajo."29

Así pues, se podrán incluir cláusulas en las que se determine como criterio de adjudicación o como obligaciones que deberán cumplirse con carácter previo a la formalización del contrato la valoración especial de las empresas que favorezcan la estabilidad en el empleo, la igualdad de oportunidades entre hombres y mujeres, la integración social de los colectivos más desfavorecidos y las que acrediten experiencia e idoneidad técnica y medios propios para el desarrollo de la prestación objeto del contrato 30.

\subsection{Contratos reservados}

A tales efectos, la Disposición Adicional $5^{\text {a }}$ de la Ley de Contratos del Sector Público admite la legalidad de estos contratos reservados al establecer que "(m)ediante Acuerdo del Consejo de Ministros o a través del órgano competente en el ámbito de las Comunidades Autónomas y de las Entidades Locales, se fijarán porcentajes mínimos de reserva del derecho a participar en los procedimientos de adjudicación de determinados contratos o de determinados lotes de los mismos a Centros Especiales de Empleo y a empresas de inserción reguladas en la Ley 44/2007, de 13 de diciembre, para la regulación del régimen de las empresas de inserción, que cumplan con los requisitos establecidos en dicha normativa para tener esta consideración, o un porcentaje mínimo de reserva de la ejecución de estos contratos en el marco de programas de empleo protegido, a condición de que al menos el 30 por ciento de los empleados de los Centros Especiales de Empleo, de las empresas de inserción o de los programas sean trabajadores con discapacidad o en riesgo de exclusión social." Esta referencia deberá incorporarse en el anuncio de licitación.

Tal y como se reconoce actualmente en nuestro ordenamiento jurídico, se pueden incorporar estas cláusulas sociales como elementos de adjudicación, bien con su inclusión a los efectos de la valoración, de desempate 0 de preferencia, e igualmente se podrán incluir como condiciones sociales impuestas a la empresa adjudicataria del contrato público ${ }^{31}$.

29.- Numerosas son las CCAA que, a través de sus Juntas Consultivas de Contratación, han elaborado informes acerca de la inclusión de este tipo de cláusulas, vid. entre otras, Informes de la Comisión Permanente 4/2001, de 23 de noviembre, sobre las cláusulas sociales en la contratación administrativa, y 2/2006, de 9 de febrero, sobre la posibilidad de incluir en los pliegos de cláusulas administrativas de la Administración de la Generalitat de Catalunya cláusulas relativas a la responsabilidad social; y recomendaciones de la Comisión Permanente 3/2005, de 7 de julio, para fomentar la igualdad de oportunidades entre las mujeres y los hombres en los contratos de la Administración, y 1/2001, de 5 de abril, sobre cláusulas sociales en la contratación administrativa. Informe 16/2014, de 1 de octubre, de la Junta Consultiva de Contratación Administrativa de la Comunidad Autónoma de Aragón sobre la incorporación en los Pliegos de los contratos de una entidad local de determinadas cláusulas sociales, y consecuencias de su eventual incumplimiento.

30.- Sirva como ejemplo de incorporación de este tipo de medidas la Ley Orgánica 3/2007, de 22 de marzo, para la igualdad efectiva de mujeres y hombres (Vigente hasta el 01 de Enero de 2017).

31.- Vid Informe JCCA núm. 59/2008 de 31 marzo 2009. JUR 2009|204232. 


\section{4.- Aspectos generales relativos al diseño del pliego}

Ya hemos señalado como las administraciones públicas tienen la obligación de utilizar normas de contratación pública, garantizando el sometimiento a los principios de publicidad, concurrencia, transparencia, confidencialidad, no discriminación y salvaguarda de la libre competencia, sin que nada impida que se incorporen otros principios de carácter social en dichos procedimientos. Recomendamos por ello evitar aquellos procedimientos en los que no existe ninguna posibilidad de iniciar un proceso competitivo.

La Recomendación formulada por la Comisión Nacional de la Competencia (actual Comisión Nacional de los Mercados y de la Competencia) es la de la utilización del procedimiento abierto ${ }^{32}$. El recurso al procedimiento restringido debería estar justificado por criterios objetivos. Cabe la opción de la utilización de un procedimiento negociado por el cual el contrato recaerá en el licitador elegido por la entidad contratante, previa consulta y negociación de los términos del contrato con uno o varios candidatos. Deben ser utilizados como vía extraordinaria porque ofrece menores garantías. Desde las administraciones públicas deben evitarse las licitaciones desiertas, quizás por una mala formulación de las especificaciones en el pliego de condiciones, por lo que ante esta situación, se deberán replantear mantener el procedimiento original con algunas modificaciones de manera que permitan abrir el procedimiento a un número suficiente de licitadores.

También serán poco recomendables, porque pueden alterarse las reglas de la competencia y obtenerse peores precios y calidad en los servicios, tanto el diálogo competitivo, como la tramitación de urgencia o los acuerdos marco y sistemas dinámicos de contratación 33 .

En todos los procedimientos de adjudicación de contratos es esencial el diseño adecuado del pliego de condiciones en el que se deberá delimitar claramente cuáles son los requisitos que se les exigirá a los licitadores para acceder a los mismos. En cualquier caso, está prohibido supeditar el acceso a la licitación a entidades que cuenten con una forma determinada, puesto que se considera

32.- Vid. Expte. S/0236/10 AYUNTAMIENTO DE CALVIA, en el que la CNC señalaba "Mientras que la provisión de los servicios de desratización, desinfección y desinsectación de Calviá se somete a un proceso de concurso público, respetando así, los principios de publicidad, concurrencia y transparencia que deben presidir la actuación pública, la provisión de los servicios de prevención y eliminación de la procesionaria del pino se ve privada de un proceso que garantice que su provisión se hará bajo los mismo principios señalados, así como el respeto a la igualdad y a la no discriminación. Este Consejo viene declarando que la competencia entre los licitadores es la manera de asegurar que las entidades del sector público se beneficien de las mejores ofertas en términos de precio, calidad e innovación de los bienes o servicios finalmente contratados. Por el contrario, la ausencia de competencia provocará ineficiencia en la gestión de los recursos públicos y por ello un mayor esfuerzo económico para la sociedad. En el caso presente las condiciones de prestación del servicio de prevención y eliminación de la procesionaria del pino serán las que se acuerden mutuamente entre el Ayuntamiento y el licitador de otro servicio distinto, el de desratización, por lo que con este procedimiento por una parte se les ha hurtado al resto de oferentes en este mercado la posibilidad de ofrecer sus servicios a un demandante de notable importancia en el mercado, lo cual distorsiona las condiciones de competencia en el mismo, y por otra parte el Ayuntamiento ha renunciado a un proceso competitivo que le podría suponer la prestación de un servicio a un menor coste, además de poder estar incurriendo en un incumplimiento de los principio de igualdad y no discriminación."

33.- GÓMEZ ASENSIO (2012). 


\section{LIMITACIONES A LA APLICACIÓN DE CLÁUSULAS SOCIALES EN LA CONTRATACIÓN PÚBLICA DESDE LA PERSPECTIVA DEL DERECHO DE LA COMPETENCIA}

una barrera de entrada a nuevos operadores. A salvo quedan las excepciones reconocidas por la Ley de Empresas de Inserción y por el TRLCSP tal y como hemos analizado con anterioridad.

Del mismo modo se prohíben las cláusulas que discriminen por razón del territorio. Así ha ocurrido por ejemplo en la Resolución (Expte. 1/2011, CONCURSO SUMINISTRO CARBURANTE) Tribunal Vasco de Defensa de la Competencia de 30 de diciembre de 2011 en relación a la preferencia por experiencias vinculadas a un ámbito geográfico ${ }^{34}$. 0 el supuesto en el que se exigía la ubicación de las instalaciones de potenciales adjudicatarios en el territorio de referencia (Resolución CNC de 18 de enero de 2010 (Expte. S/0014/07. Gestión de Residuos Sanitarios) ${ }^{35}$.

Se deberá evitar, en cualquier caso también, la inclusión de requisitos técnicos y económicos innecesarios o excesivos en relación con los bienes, o servicios objeto del contrato, incluidas las referencias a tipologías, marcas o especificaciones técnicas ${ }^{36}$, a no ser que se contemplen legalmente, y evitar igualmente, exigencias que supongan una carga económica desproporcionada, como ocurrió en la STS de 11 de julio de 200637. Se podrá utilizar como criterio de adjudicación la calidad de la oferta

34.- Informe 9/09, de 31 de marzo de 2009 de la JCCA, relativo a la "Aplicación del criterio de arraigo local o de vecindad de la empresa como requisito de aptitud, de solvencia o como criterio de adjudicación en los contratos" en que se estableció como criterio de adjudicación,, a) Precio: $60 \%$,b) Plazo de ejecución: $20 \%$, c) Conocimiento empresarial de la zona $20 \%$, concluyó que "(e)l origen, domicilio social o cualquier otro indicio del arraigo territorial de una empresa no puede ser considerado como condición de aptitud para contratar con el sector público." $Y$ en segundo lugar, "(i)gualmente no pueden ser utilizadas como criterio de valoración circunstancias que se refieran a alguna de las características de la empresa señaladas en la conclusión anterior."

35. - En este caso se repartieron el mercado a través de la creación de UTEs, para concurrir a las licitaciones públicas. En el pliego de concreción de hechos se señala que resultó "acreditada una infracción del artículo 1.1 c) de la Ley 16/1989, de 17 de julio de Defensa de la Competencia, consistente en un acuerdo para repartirse los clientes públicos del mercado de gestión de residuos sanitarios de la que eran responsables las empresas Consenur, SA; Cespa, Gestión de Residuos, SA; Interlun, SL y Sistemas Integrales Sanitarios. Dicha resolución acuerdó imponer a Cespa una multa de dos millones de euros y asimismo otra infracción del artículo 1 de la Ley 16/89 de 17 de julio de defensa de la Competencia consistente en un pacto de no competencia de la que es responsable CESPA para excluir del mercado a la empresa ATHISA, acordándose imponer a CESPA una multa de 600.000€ y ordenó la publicación de dicha resolución a costa de las sancionadas en el BOE y en dos diarios de información general, entre aquellos de mayor difusión de ámbito nacional". Recurrido ante la Audiencia Nacional esta estimó parcialmente el recurso en Sentencia de 15 de octubre de 2012, dejando sin efecto la sanción impuesta por lo que se refiere al pacto de no competencia, reduciendo el importe de la sanción impuesta en base al art. 1.1.c) de la LDC, por reparto de mercado, a la cantidad de 569.925,92 $€$, y las costas de la publicación de cuenta de la Administración pública.

36.- Vid Recomendación de 26 mayo 2008. JUR 20081299032 de la JCCA en relación a procedimientos de adjudicación de los contratos para la adquisición o el arrendamiento de ordenadores y demás equipos informáticos en la que se indica que no se especifique una determinada marca de procesadores ni se limite a la expresión de una determinada frecuencia de reloj.

37.- Tribunal Supremo (Sala de lo Contencioso-Administrativo, Sección4a), Sentencia de 11 julio 2006 (RJ 2006l8471), "Es tajante el art. 87 de la LCAP (RCL 1995, 1485, 1948) al establecer la necesidad de que los pliegos de cláusulas administrativas particulares del concurso fijen los criterios objetivos que han de servir de base para la adjudicación los cuales se indicarán por orden decreciente de importancia y por la ponderación que les atribuya. Tal exigencia obstaculiza la discrecionalidad administrativa en la adjudicación del concurso por cuanto la administración para resolverlo ha de sujetarse a la baremación previamente determinada. Su discrecionalidad solo juega con anterioridad a la adjudicación al decidir con libertad de criterio cuáles son los criterios objetivos más significativos respetando, eso sí, las reglas esenciales que impregnan nuestra actual normativa sobre contratación administrativa a partir de la transposición de las múltiples Directivas sobre la materia: publicidad, libre concurrencia y transparencia administrativa.

Por su parte el art. 89 de la LCAP declara que el concurso se adjudicará tras motivar, en todo caso, con referencia a los criterios de adjudicación del concurso que figuren en el pliego. Constituye pues, la motivación, conforme al art. 54.2 Ley de Régimen Jurídico y Procedimiento Administrativo Común ( RCL 1992, 2512, 2775 y RCL 1993, 246) , (LRJ-PAC) un elemento esencial para evitar la arbitrariedad, al tiempo que permite a los demás interesados conocer los argumentos utilizados por la mesa de contratación para, en su caso, impugnar la adjudicación. En tal sentido resulta claro el contenido del art. 94 LCAP que obliga no sólo a comunicar a los demás participantes en la licitación la adjudicación del contrato sino, incluso, a notificar, previa petición de los interesados, los motivos del rechazo de su proposición y las características de las proposiciones del adjudicatario determinantes de la adjudicación a su favor. Motivación de la decisión que habrá de ser razonada y fundada con arreglo a los criterios del pliego."

CIRIEC-España, Revista de Economía Pública, Social y Cooperativa 
contractual, pero no los niveles de calidad obtenidos por las empresas en prestaciones semejantes a la del objeto del contrato, es "requisito que puede justificar la solvencia del empresario en la fase de verificación de su aptitud, pero no puede utilizarse como criterio de valoración de las ofertas."38.

En este punto es destacable la Sentencia de 25 mayo 2015 del TS (Sala de lo ContenciosoAdministrativo, Sección 7a) RJ/201512903 en la que en el pliego de condiciones se incluyó como factor determinante de la atribución automática de puntos, el que las ofertas de los licitadores incluyeran un Centro Especial de Empleo, cuya existencia de debía justificar documentalmente en el sobre correspondiente a los mismos. La mesa de contratación no asignó los puntos referidos al Centro Especial de Empleo a una de las proposiciones al no considerar acreditada tal circunstancia, puesto que, de la documentación contenida en el sobre correspondiente, no se desprendía que la empresa excluida dispusiera de dicho centro, ya que según se desprendía de las escrituras aportadas, parecía pertenecer a otra sociedad distinta a la licitadora. Tras recurrir ante el Tribunal Administrativo Central de Recursos Contractuales (TACRC), se sostuvo por ésta, que el órgano de contratación había incurrido en un error, que se debía considerar cumplido el requisito, ya que no se trataba de un criterio de solvencia, sino de valoración de la oferta puesto que estaba suficientemente acreditado. El órgano de contratación consideró que a la vista de la documentación presentada no había ninguna prueba de que el Centro le perteneciera, señalando además que de conformidad con lo previsto en el "artículo 81 del Real Decreto 1098/2001, de 12 de octubre , por el que se aprueba el Reglamento General de la Ley de Contratos de las Administraciones Públicas, no cabe subsanación de defectos u omisiones respecto del contenido de los sobres $n^{\circ} 2$ (valoración de la oferta según criterios evaluables subjetivamente) y $n^{\circ} 3$ (valoración de la oferta según criterios evaluables automáticamente)." EI TACRC estimó en parte el recurso de la empresa no adjudicataria al entender "que, con independencia de la ubicación en la que se hubiera exigido la acreditación documental de la existencia de un Centro Especial de Trabajo, su naturaleza es la propia de un requisito de solvencia, y como tal ha de ser tratado (en este sentido cabe citar, en un supuesto análogo, la Resolución de este Tribunal núm. 85/2012), lo que implica, a los efectos que nos ocupan, que la eventual omisión de la prueba documental de la existencia de este Centro Especial de Empleo debe considerarse como un defecto subsanable."

La previsión de los derechos de preferencia y tanteo no puede obviarse porque puede causar graves restricciones a la competencia en la adjudicación del contrato ${ }^{39}$. El derecho de preferencia se traduce en la concesión de ventajas al vigente titular del contrato, atribuyendo, por ejemplo, por el mero hecho de su titularidad, una mayor ponderación a su oferta en el caso de que ésta obtenga una valo-

38.- Vid. Informe 53/97, de 2 de marzo de 1998 de la JCCA, relativo a "Los criterios objetivos de valoración de las ofertas y su distinción de los medios en virtud de los cuales se determina la solvencia de las empresas. El criterio objetivo de la calidad" en el que concluye que "puede figurar como tal en los pliegos de cláusulas administrativas particulares, a no ser que con el término calidad se esté aludiendo a otro requisito distinto, en particular la experiencia, configurado como requisito de solvencia."

39.- GÓMEZ ASENSIO, 2012. 
ración similar a la de otros competidores. Por su parte, el derecho de tanteo permite al beneficiario subrogarse en la posición del licitador que resulte adjudicatario, sustituyéndole en el contrato 40 .

\section{5.- Cuestiones relativas a la adjudicación y ejecución del contrato}

En cuanto a la adjudicación y ejecución, es primordial fijar una ponderación adecuada de las variables básicas, lo que deberá permitir la existencia de un margen lo suficientemente amplio para que la competencia no se vea afectada. De hecho, una ponderación inadecuada de la variable precio, podría incrementar sustancialmente el coste del servicio y la calidad del mismo. Del mismo modo, si se produce un reflejo inadecuado del impacto del precio o tarifa ofertados en el presupuesto seleccionado como base del proyecto, tendrá los mismos efectos sobre el precio y la calidad del servicio.

Se deberá garantizar en todo caso la igualdad de trato y el principio de no discriminación entre los licitadores, quedando expresamente prohibido introducir elementos que favorezcan indebidamente a las empresas ya establecidas o que lleven tiempo trabajando en el sector, lo que puede llevar a una discriminación entre operadores.

Deberán fijarse límites a los precios, tarifas u otras características del servicio con el fin de evitar la presencia de "ofertas temerarias".

Además, deberá evitarse otorgar un excesivo peso de criterios que no sean relevantes para la ejecución de la prestación o que impongan costes adicionales a los licitadores en relación con el vigente titular del contrato (Vid. Guía CNC 2010).

Tampoco debe limitarse la adjudicación a la oferta con "precio más bajo", deberá utilizarse el "sistema de oferta económicamente más ventajosa", con el fin de que se escoja aquella que pueda satisfacer de mejor modo los objetivos del contrato, el cumplimiento de criterios sociales, medioambientales... como elementos que pueden afectar al valor de una oferta, porque, de hecho, estos elementos cumplen determinadas funciones y además, supondrán un coste económico.

40.- Vid. Informe 57/10, de 15 de diciembre de 2011 JCCA sobre la "Posibilidad de incluir en los pliegos para la adjudicación de contratos de obra una opción de derecho de tanteo a favor de una empresa que tiene la condición de accionista de una sociedad mixta municipal y que es a su vez una empresa constructora." En este informe concluyó que "la inclusión de un derecho de tanteo a favor de la empresa constructora que suscriba las acciones de la Empresa Municipal de la Vivienda, en los futuros contratos de obras que la misma Empresa Municipal pueda adjudicar, no puede admitirse por suponer una preferencia contraria a los principios de igualdad y no discriminación." 
Los criterios de valoración deberán reflejar claramente los objetivos perseguidos por el contrato evitando la confusión de los medios con los fines incorporando elementos confusos. La posibilidad de modificar a posteriori por parte de la entidad adjudicadora de ciertos elementos secundarios vinculados al criterio de adjudicación, si bien algunas sentencias han admitido su incorporación (Vid. STPI de 25 de febrero de 2003, Renco, T-4/2001 §§83-87), no es menos cierto que el TJCE señaló que, aunque posible (siempre sujetándola a unos requisitos predeterminados), la concreción no puede modificar los criterios de adjudicación definidos previamente, y esta modificación no podrá contener elementos que de haberse conocido en el momento de la preparación de las ofertas, podrían haber influido en su desarrollo. La finalidad en todo caso es respetar el principio de igualdad de trato de los operadores económicos y de la obligación de transparencia de cualquier procedimiento de licitación. EI TS en cambio ha considerado lícita esta concreción, en base al amplio criterio de discrecionalidad con que cuentan las Administraciones públicas en la fijación de la ponderación ${ }^{41}$.

Otros elementos que deberán eliminarse en esta fase de adjudicación y ejecución son, por ejemplo, la no concreción del sistema de atribución de puntuación a los criterios de valoración, porque puede determinar un margen de discrecionalidad tan elevado, que puede conducir a restricciones graves de la competencia como las barreras de acceso al procedimiento por parte de otros licitadores. También el conocimiento ex ante del umbral de anormalidad de las ofertas puede llevar a una concertación de precios por parte de los licitadores, e incluso, puntuar elementos que ya fueron valorados en la fase previa, cuando se valoró la solvencia.

Tampoco es posible utilizar el criterio de implantación de las empresas en un territorio como discriminatoria a la hora de valorar las ofertas, obteniendo una bonificación en la valoración de las ofertas por esta circunstancia. El principio de no discriminación consagrado en el TRLCSP (art. 1) y el principio de igualdad y transparencia recogido en el art. 139 del mismo texto legal, claramente indican que "Ios órganos de contratación darán a los licitadores y candidatos un tratamiento igualitario y no discriminatorio y ajustarán su actuación al principio de transparencia"42, por lo que no está permitido discriminar ofertas por razón de las características que puedan tener cada una de las empresas licitadoras, ya sea domicilio social o el especial arraigo en una determinada localidad o territorio 43 . Pero además no se puede obviar que en la definición en los pliegos de los criterios de adjudicación, no son admisibles tampoco aquellos que supongan una clara discriminación en base a lo dispuesto en el art. 150 TRLCSP y deben estar directamente vinculados, en todo caso, al objeto del contrato ${ }^{44}$, a salvo, claro está la posibilidad de inclusión de cláusulas sociales.

41.- STS 5 de marzo de 2002 (RCA 99 y 104/1998, acumulados).

42.- En el mismo sentido vid. art. 123 LCSP anterior.

43.- Vid. Informe núm. 9/2009 de 31 marzo. JUR 20091204245, JCCA.

44.- Este precepto señala al efecto que "Artículo 150. Criterios de valoración de las ofertas.

1. Para la valoración de las proposiciones y la determinación de la oferta económicamente más ventajosa deberá atenderse a criterios directamente vinculados al objeto del contrato, tales como la calidad, el precio, la fórmula utilizable para revisar las retribuciones ligadas a la utilización de la obra o a la prestación del servicio, el plazo de ejecución o entrega de la prestación, el coste de utilización, las características medioambientales o vinculadas con la satisfacción de exigencias sociales que respondan a necesidades, definidas en las especificaciones del contrato, propias de las categorías de población especialmente desfavorecidas a las que pertenezcan los usuarios o beneficiarios de las prestaciones a contratar, la rentabilidad, el valor técnico, las características estéticas o funcionales, la disponibilidad y coste de los repuestos, el mantenimiento, la asistencia técnica, el servicio postventa u otros semejantes." 


\section{LIMITACIONES A LA APLICACIÓN DE CLÁUSULAS SOCIALES EN LA CONTRATACIÓN PÚBLICA DESDE LA PERSPECTIVA DEL DERECHO DE LA COMPETENCIA}

La JCCA, en su Informe núm. 12/2011 de 28 octubre. JUR 2011 1441395 se pronunció sobre la aplicación de un criterio de adjudicación que valorara el porcentaje de trabajadores en situación de paro que se contrataría para la ejecución del contrato, señalando que "no es admisible, de conformidad con el artículo 134.1 de la Ley de Contratos del Sector Público (RCL 2007, 1964), el establecimiento en los pliegos de cláusulas administrativas particulares de criterios de adjudicación que valoren el porcentaje de mano de obra desempleada que se contratará para la ejecución del contrato." A lo que añadía en sus conclusiones, que por el contrario, si es admisible, "el establecimiento de condiciones de ejecución que favorezcan la lucha contra el desempleo siempre que no incurran en discriminación." (ex. art. 102 LCSP 2007). En el mismo sentido se pronuncia la JCCA en su Informe núm. 3/2009 de 25 septiembre. JUR 20091443232 en relación a la posibilidad de establecer como condición de ejecución del contrato la utilización de un determinado porcentaje de personas desempleadas que se encuentren inscritas en las oficinas de empleo de una localidad y de establecer un criterio de adjudicación del contrato que consistiese en la valoración del compromiso de emplear en su ejecución personas desempleados inscritas en una determinada oficina de empleo. Ámbito de aplicación de criterios sociales. La Junta se pronunció señalando que no son admisibles las condiciones, en la ejecución ni en los criterios de adjudicación, que exijan la contratación de un cierto porcentaje de personas que estén inscritas como demandantes de empleo en las oficinas de empleo de un determinado lugar geográfico en la medida que implique discriminación respecto del resto de trabajadores nacionales o bien originarios del resto de Estados de la Unión Europea. En todo caso sí que sería admisible establecer condiciones de ejecución que favorezcan la lucha contra el desempleo, si no incurren en discriminación.

La fijación de plazos excesivamente largos de vigencia del contrato crea una barrera de entrada a nuevos operadores que no podrán acceder al mercado durante el tiempo que dure el contrato. Pero no podemos olvidar que si los plazos son excesivamente cortos, ello puede dificultar la amortización de las inversiones que sean necesarias para ejecutar el contrato. Si atendemos a lo dispuesto en el art. 23 TRLSP, en el que se señala que "la duración de los contratos del sector público deberá establecerse teniendo en cuenta la naturaleza de las prestaciones, las características de su financiación y la necesidad de someter periódicamente a concurrencia la realización de las mismas", que podrán prever una o varias prórrogas, "siempre que sus características permanezcan inalterables durante el período de duración de éstas y que la concurrencia para su adjudicación haya sido realizada teniendo en cuenta la duración máxima del contrato, incluidos los períodos de prórroga"45, y a lo dispuesto en

45.- Vid. TSTSJ de Islas Canarias, Las Palmas (Sala de lo Contencioso-Administrativo, Sentencia núm. 146/2014 de 11 julio. JUR 2015|13056 en la que se trata un problema relativo a un contrato de gestión del servicio público de abastecimiento de agua en la que inicialmente, de mutuo acuerdo, se impuso una prórroga. "La problemática empieza cuando el Ayuntamiento pretende continuar con las prórrogas y la concesionaria disiente de ello. En el contrato de resolución se estableció un primer plazo de seis meses de prórroga, a partir, de ese plazo, la Administración no podía imponer al otro contratista indefinidamente la prestación del contrato, en contra de su voluntad. Tengamos en cuenta que la resolución se pactó de mutuo acuerdo, y por tanto, sería un abuso de derecho imponer la continuación del contrato durante cuatro años más. Pero la realidad es que las prórrogas iniciales fueron aceptadas por ambas partes, durante el año 2009 y 2010 , los problemas surgen cuando la concesionaria no quiere prestar el servicio en las condiciones que se le imponen y reclama por una serie de conceptos, que el Ayuntamiento no acepta.

La continuación de la concesionaria en la prestación del servicio "sine die" es contraria a lo estipulado en la resolución contractual de mutuo acuerdo de 19 de junio de 2009, en la que se pactaba un plazo de 6 meses. Es evidente que no se puede imponer la prórroga "sine die" y si bien, la concesionaria está obligada a continuar prestando el servicio hasta que se adjudique nuevamente el contrato, esta condición no puede ser indefinida, porque ese no fue el pacto, por el contrario, el Ayuntamiento debe ir realizando los actos necesarios para entender cumplida la citada condición. Por lo que en este particular ha de estimarse el recurso, la condición "sine die" impuesta no puede ser indefinida, y por el Ayuntamiento, en todo caso, deben de cumplirse con los actos necesarios para dar por extinguido el contrato. En este particular se anula la Resolución de 30 de junio de 2011, al imponer una prórroga indefinida del contrato resuelto, en contra de la voluntad expresamente manifestada de la otra parte."

CIRIEC-España, Revista de Economía Pública, Social y Cooperativa

ISSN: 0213-8093

№ $87 / 2016$, pp. 177-202 
la Guía CNC 2010, para reducir los riesgos deben evitarse prórrogas sobrevenidas, como contrapartida por la incorporación de modificaciones sustanciales del contrato, a menos que exista una razón de imperiosa necesidad, deben ser totalmente excepcionales, y deberá incorporarse esta posibilidad en los pliegos del contrato. En cualquier caso, su justificación debe ser objetiva y utilizar criterios, por ejemplo, directamente relacionados con el periodo de amortización de las inversiones o de los activos vinculados al contrato 46 .

\section{6.- Valoración final}

Tras este breve análisis de las reglas de la competencia aplicables a la legislación relativa a los contratos del sector público y la utilización de cláusulas sociales, consideramos que hemos destacado el papel esencial desempeñado por los poderes públicos, cuya actividad, y las decisiones adoptadas, inciden directamente en la libre concurrencia en el mercado.

Los poderes públicos deberán velar porque exista plena igualdad en el acceso a la información, así como el acceso a cualquier dato relativo a la subsanación de errores en los diferentes trámites del procedimiento. Se les deberá facilitar toda la información relativa a las modificaciones sobrevenidas, prestaciones complementarias, cambio en los precios.

Del análisis realizado se desprende el amparo legal a determinado tipo de cláusulas sociales, como el reconocimiento y exigencia de empresas de inserción o centro especiales de empleo para el acceso a la licitación, o la incorporación de cláusulas sociales de desempate frente a la igualdad de proposiciones con ofertas económicas semejantes. Queda claro pues, que no será el criterio del precio más bajo el determinante en la adjudicación, sino la propuesta económica más ventajosa, en la que se incluya, criterios sociales, medioambientales, de comercio justo, de igualdad de género, de inclusión de sectores en riesgo de exclusión social.

46.- En este punto, debemos reseñar el IPN/CNMC/010/15 Anteproyecto de Ley de Contratos del Sector Público que fija las pautas que debía seguir el TRLCSP vigente para evitar restricciones a la libre competencia, así, señalaba la CNMC, que la duración debe ser siempre justificada sin referencias vacías de contenido, por otra parte, los plazos máximos no son obligatorios, es decir, no deben ser agotados necesariamente, y es conveniente determinar la duración expresa de la prórroga, diferenciada de la duración del contrato. El recurso a las prórrogas debe ser un mecanismo totalmente excepcional y siempre que dicha posibilidad figure en los pliegos, con ello se evitará un cierre del mercado por largos y potencialmente indefinidos periodos de tiempo. Deben evitarse las prórrogas sobrevenidas por una introducción de modificaciones sustanciales del contrato, a no ser que sea absolutamente necesaria, y en cualquier caso, deberá ser acordada por el órgano de contratación, y será obligatoria para el empresario siempre que se produzca con al menos dos meses de antelación a la finalización del contrato. Sin embargo la CNMC este punto lo considera problemático, a no ser que esta obligatoriedad para el adjudicatario venga dada por la necesidad de continuar el servicio. Reclamaba la CNMV una aclaración en relación con la aplicación de revisión de prórrogas de los contratos con duración mayor de dos años. 
Por todo ello podemos declarar como cláusulas prohibidas, a partir del análisis de la legislación en materia de defensa de la competencia y de la normativa reguladora de los contratos del sector público, las que supediten el acceso a la licitación a una forma jurídica determinada, o la exclusión de la misma a los empresarios individuales. Tampoco podrán introducirse cláusulas que discriminen por razón del territorio, o por la experiencia vinculada al territorio. Del mismo modo se prohíben las cláusulas que exijan que la ubicación de las instalaciones de los posibles adjudicatarios esté en un territorio determinado. Por supuesto no podrán hacer referencia las cláusulas a tipologías, marcas o especificaciones técnicas en relación con los bienes objeto del contrato. No podrá exigirse la contratación de seguro de responsabilidad de cuantía excesiva en relación con el objeto del contrato. Se prohíbe la introducción de elementos que favorezcan a empresas ya establecidas o que lleven tiempo trabajando en el sector, atribuyendo una ponderación excesiva a parámetros que pueden llevar a una discriminación entre licitadores en la fase de adjudicación y ejecución del contrato. Se deberán evitar las cláusulas que induzcan a confusión entre los criterios de adjudicación y de solvencia y en ningún caso se podrá considerar, a los efectos de la adjudicación del contrato, el grado de satisfacción de la Administración con dicha ejecución ya que contribuirá a discriminar y crear barreras de entrada contra potenciales contratantes. No resulta admisible la inclusión de la experiencia como elemento a valorar para la adjudicación del contrato puesto que ésta guarda relación con el contratista y la evaluación de la capacidad debe realizarse en la fase de admisión y no en la adjudicación. Se podrá utilizar como criterio de adjudicación el de la calidad de la oferta contractual, pero en ningún caso los niveles de calidad obtenidos por las empresas en prestaciones semejantes a la del objeto del contrato. En ningún caso podrá utilizarse una cláusula de derecho de preferencia o de concesión de ventajas al vigente titular del contrato, al que se le otorga una mayor puntuación, por el mero hecho de su titularidad en el caso de que su oferta obtenga una valoración similar a la de sus competidores. Tampoco debe ser utilizada la cláusula de tanteo en la medida en que permite al beneficiario subrogarse en la posición del licitador que resulte adjudicatario, sustituyéndole en el contrato. Deberán fijarse límites a los precios, tarifas u otras características del servicio con el fin de evitar la presencia de "ofertas temerarias".

Deberá evitarse otorgar un peso excesivo a criterios no relevantes para la prestación del servicio o que impongan costes adicionales a los licitadores en relación con el vigente titular del contrato. La adjudicación no deberá realizarse a la propuesta con "precio más bajo", sino que deberá utilizarse el sistema de oferta económicamente más ventajosa con el fin de que se escoja la que mejor pueda satisfacer los objetivos del contrato, cumplimiento de criterios sociales, medioambientales,...

Por otra parte, deberán concretarse claramente el sistema de atribución de puntuación a los criterios de valoración con el fin de evitar un amplio margen de discrecionalidad que produzca restricciones de la competencia. Se deberá evitar el conocimiento ex ante del umbral de anormalidad de las ofertas, que puede llevar a una concertación de precios entre licitadores. Y por último, deberán evitarse plazos excesivamente largos que impidan a otros operadores acceder al mercado, y también los excesivamente cortos que impidan una amortización adecuada de las inversiones realizadas. Del mismo deberán evitarse las modificaciones de las condiciones de la contratación, a no ser que se deba a una imperiosa necesidad, y deberá incluirse, en su caso, la posibilidad de prórroga y en qué condiciones, para evitar las barreras a las que nos acabamos de referir. 


\section{Bibliografía}

BURZACO SAMPER, M. (2016): "Contrataciones públicas socialmente responsables: la necesidad de reconsiderar el potencial de la contratación pública en la consecución de objetivos sociales", CIRIEC-España, Revista de Economía Pública, Social y Cooperativa, 86, 281-310.

GARCÍA ARÉJULA, J.M. \& BAKAIKOA AZURMENDI, B. (2014): "El papel de la Economía Social en la contratación pública del Gobierno vasco entre 2010 y 2012", CIRIEC-España, Revista de Economía Pública, Social y Cooperativa, 82, 207-232.

GARCÍA ARÉJULA, J.M. \& BAKAIKOA AZURMENDI, B. (2016): "Contratos públicos adjudicados a sociedades cooperativas en el País Vasco entre 2010 y 2012", REVESCO, Revista de Estudios Cooperativos, 120, 76-98.

GÓMEZ ASENSIO, C. (2012): La Mejora Regulatoria (Better Regulation): Aplicaciones en Materia de Contratación Pública, Tirant lo Blanch.

LESMES ZABALEGUI, S. (2005): "Contratación pública y discriminación positiva. Cláusulas sociales para promover la igualdad de oportunidades entre mujeres y hombres en el mercado laboral", Lan harremanak: Revista de relaciones laborales, $13, \mathrm{~N}^{\circ}$ dedicado a: Mujeres y mercado de trabajo, 53-86.

MEDINA JURADO, P. (2010): "Las cláusulas sociales en la contratación pública: retos y perspectivas", Revista Cemci, 7. Mar-jun.

MORENO MOLINA \& PLEITE GUADAMILLAS (2011): La nueva Ley de contratos del sector público. Estudio sistemático, Edit. La Ley-Actualidad.

PANIAGUA ZURERA (2013): "Las empresas de inserción sociolaboral y las cláusulas sociales en la contratación pública: dos instrumentos necesarios para la innovación social hacia el desarrollo", REVESCO, Revista de Estudios Cooperativos, 112, № Homenaje al Profesor Alfonso Carlos Morales Gutiérrez, 176-212.

PAREJO ALFONSO, L. (2004): "Servicios públicos y servicios de interés general: la renovada actualidad de los primeros", Revista de Derecho Europeo, 7, Ejemplar dedicado a: 'Servicios públicos, privatizaciones y liberalizaciones en la Unión Europea', 51-68.

RIERA LÓPEZ (2013): "Contratos menores: rasgos característicos, menciones especiales y consecuencias de un uso abusivo", http://www.auditoriapublica.com/hemeroteca/Pag\%206168\%20N\%2061.pdf. (último acceso octubre 2015).

VAÑÓ VAÑÓ, M.J. (2014): "El respeto a las reglas de la competencia en la incorporación de las cláusulas sociales en la prestación de servicios públicos", XV Congreso de Investigadores en Economía Social de CIRIEC-España, Santander. Disponible en: http://ciriec.es/eventos/xv-congreso-deinvestigadores-en-economia-social-y-cooperativa/ 